\title{
An ab Initio Study on the Oxidative Coupling of Methane over a Lithium-Doped MgO Catalyst: Surface Defects and Mechanism
}

\author{
Michael A. Johnson, Eugene V. Stefanovich, ${ }^{\dagger}$ and Thanh N. Truong* \\ Department of Chemistry, University of Utah, Salt Lake City, Utah 84112 \\ Received: December 17, $1996^{\otimes}$
}

\begin{abstract}
We present a study on the catalytic cycle responsible for coupling of methane by molecular oxygen over a lithium-doped magnesium oxide catalyst. To elucidate the mechanism by which methyl radicals are produced and the active sites are regenerated, geometries and energies of relevant reaction intermediates were determined using an $a b$ initio embedded cluster model. Our results suggest a new mechanism that requires only one active site and does not involve the energetically costly process of creating lattice vacancies. This mechanism is more consistent with the available experimental data than the Ito-Lunsford mechanism proposed earlier.
\end{abstract}

\section{Introduction}

Efficient utilization of methane, the primary component of natural gas, is becoming an immediate goal as we face issues of diminishing natural resources. Unfortunately, the remote locations of most natural gas reserves make transportation of this fuel economically unreasonable. ${ }^{1}$ One means to exploit the remote gas sources is to first convert methane to more useful higher carbon products that can easily be transported to the consuming facility. However, existing methane conversion methods ${ }^{2}$ have proven to be prohibitively expensive. Thus, developing a less expensive catalytic conversion method is of great interest and technological significance.

Numerous research efforts have been devoted to the design of efficient metal oxide catalysts for methane conversion with high selectivity to $\mathrm{C}_{2}$ compounds and low operational temperatures (for review, see refs 1 and 3). Among these catalysts, lithium-doped magnesium oxide $(\mathrm{Li} / \mathrm{MgO})$ is of particular interest for several reasons. First, $\mathrm{Li} / \mathrm{MgO}$ effectively converts methane to ethane and ethylene in the presence of oxygen at about $700{ }^{\circ} \mathrm{C} .{ }^{4-6}$ Second, the highly ionic character of the chemical bond in $\mathrm{MgO}$ makes these crystals tractable by current quantum mechanical methods, ${ }^{7}$ thus making $\mathrm{Li} / \mathrm{MgO}$ an ideal theoretical model for studying catalysis. Finally, a great deal of experimental and theoretical data has been compiled about point defects in $\mathrm{MgO}$, including their electronic structure and chemical reactivity. Specifically, experimental studies on the reaction kinetics showed that hydrogen abstraction from methane over some reactive site on the $\mathrm{Li} / \mathrm{MgO}$ surface is most likely to be the rate-limiting step in the conversion of methane to ethane. ${ }^{8,9}$ The activation energy for such a reaction was reported in the range from 20 to $28 \mathrm{kcal} / \mathrm{mol}$ depending on the reaction conditions. ${ }^{9,10}$ Although some role of surface $\mathrm{F}$ centers as active sites has been suggested, ${ }^{11,12}$ numerous studies conclude that the surface $\mathrm{O}^{-}$ion (or localized electronic hole) can be responsible for hydrogen abstraction. There are several possible modes of hole localization on the $\mathrm{MgO}$ surface discussed in the literature. Electronic holes may be self-trapped on the MgO(001) surface $^{13}$ and additionally stabilized by the presence of $\mathrm{Mg}^{2+}$ vacancies $^{14,15}$ or in the low-coordinated sites. ${ }^{13,16-19}$ In the bulk and on the surface of lithium-doped $\mathrm{MgO}, \mathrm{Li}^{+}$ions occupy $\mathrm{Mg}^{2+}$ sites and stabilize the nearby $\mathrm{O}^{-}$species resulting in $\left[\mathrm{Li}^{+} \mathrm{O}^{-}\right]$defects. ${ }^{15,20-24}$ Although theoretical studies suggest

$\dagger$ On leave from the Institute of Chemical Physics, University of Latvia, 19 Rainis blvd, Riga LV1586, Latvia.

* Corresponding author.

${ }^{\otimes}$ Abstract published in Advance ACS Abstracts, April 1, 1997.

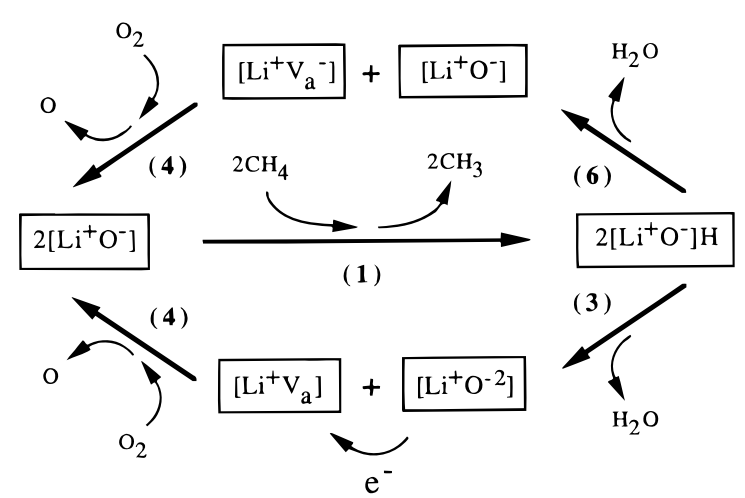

(3a)

Figure 1. Two alternative cycles of the Ito-Lunsford mechanism. Both cycles begin with the two neighboring $\left[\mathrm{Li}^{+} \mathrm{O}^{-}\right]$defects shown at the left followed by reaction 1 . The lower channel involves proton migration between defects. The upper loop shows an analogous reaction with a mobile hydrogen atom.

that $\left[\mathrm{Li}^{+} \mathrm{O}^{-}\right]$defects can form aggregates, ${ }^{25}$ the absence of spin exchange and dipolar broadening in the ESR spectra indicated that the $\left[\mathrm{Li}^{+} \mathrm{O}^{-}\right]$centers must be well separated from one another by at least $8-10 \AA .^{20}$ At elevated reaction temperatures, electron holes can leave bulk $\mathrm{Li}^{+}$impurities, become localized on the surface, and thus increase the number of reactive centers. ${ }^{1}$ However, the concentration and distribution of catalytic sites on the surface are unknown, and our understanding in regard to the mechanism of the entire catalytic cycle, including regeneration of the active site, is still incomplete at best.

To our knowledge, the only mechanism for the oxidative coupling of methane above the $\mathrm{Li} / \mathrm{MgO}$ catalyst was proposed by Ito and Lunsford., 5 This mechanism is shown schematically in Figure 1. In this figure, and throughout the text, we commonly use notation in which brackets enclose the surface defect, and species indicated outside the brackets are adsorbates at the defect site. In more detail, the Ito-Lunsford mechanism implies participation of at least two trapped-hole $\left[\mathrm{Li}^{+} \mathrm{O}^{-}\right]$surface defects and consists of three steps. The first step is hydrogen abstraction by $\left[\mathrm{Li}^{+} \mathrm{O}^{-}\right]$defects with formation of two surface $\mathrm{OH}^{-}$groups

$$
2\left[\mathrm{Li}^{+} \mathrm{O}^{-}\right]+2 \mathrm{CH}_{4}(\mathrm{~g}) \rightarrow 2\left[\mathrm{Li}^{+} \mathrm{O}^{-}\right] \mathrm{H}+2 \mathrm{CH}_{3}(\mathrm{~g})
$$

The resultant methyl radicals couple in the gas phase to form ethane

$$
2 \mathrm{CH}_{3}(\mathrm{~g}) \rightarrow \mathrm{C}_{2} \mathrm{H}_{6}(\mathrm{~g})
$$


The second step involves dissociation of one surface $\mathrm{OH}^{-}$group into a lattice $\mathrm{O}^{2-}$ ion and a mobile surface proton. This proton migrates to another $\mathrm{OH}^{-}$to form a water molecule which desorbs from the surface, leaving behind an anion vacancy $\mathrm{V}_{\mathrm{a}}$. Thus, step two can be represented by the single equation

$$
2\left[\mathrm{Li}^{+} \mathrm{O}^{-}\right] \mathrm{H} \rightarrow\left[\mathrm{Li}^{+} \mathrm{O}^{2-}\right]+\left[\mathrm{Li}^{+} \mathrm{V}_{\mathrm{a}}\right]+\mathrm{H}_{2} \mathrm{O}(\mathrm{g})
$$

The final step is regeneration of the active site, which involves electron transfer to the anion vacancy

$$
\left[\mathrm{Li}^{+} \mathrm{O}^{2-}\right]+\left[\mathrm{Li}^{+} \mathrm{V}_{\mathrm{a}}\right] \rightarrow\left[\mathrm{Li}^{+} \mathrm{O}^{-}\right]+\left[\mathrm{Li}^{+} \mathrm{V}_{\mathrm{a}}^{-}\right]
$$

and dissociative chemisorption of oxygen

$$
\left[\mathrm{Li}^{+} \mathrm{V}_{\mathrm{a}}^{-}\right]+\mathrm{O}_{2}(\mathrm{~g}) \rightarrow\left[\mathrm{Li}^{+} \mathrm{O}^{-}\right]+\mathrm{O}
$$

Thus, two iterations of the Ito-Lunsford cycle result in the following conversion

$$
4 \mathrm{CH}_{4}(\mathrm{~g})+\mathrm{O}_{2}(\mathrm{~g}) \stackrel{\mathrm{Li} / \mathrm{MgO}}{\longrightarrow} 2 \mathrm{C}_{2} \mathrm{H}_{6}(\mathrm{~g})+2 \mathrm{H}_{2} \mathrm{O}(\mathrm{g})
$$

While the Ito-Lunsford mechanism successfully incorporates hydrogen abstraction from methane and regeneration of the reactive center, certain features of this mechanism appear to be unlikely. First, it requires removal of a lattice oxygen from the lattice site which is expected to be highly endothermic. For example, theoretical estimates for the removal of an oxygen atom from the $\mathrm{MgO}(001)$ surface are well in excess of $170 \mathrm{kcal} /$ mol. ${ }^{13,27-29}$ Therefore, in contrast to experimental data, oxygen removal and not hydrogen abstraction would be the rate-limiting step in this catalytic cycle. ${ }^{5}$ Second, migration of a proton, as in reaction 3, requires substantial energy to overcome a strong electrostatic attraction between oppositely charged species $\left[\mathrm{Li}^{+} \mathrm{O}^{2-}\right]$ and $\mathrm{H}_{\mathrm{ads}}{ }^{+}$. Third, a large separation between $\left[\mathrm{Li}^{+} \mathrm{O}^{-}\right]$ centers implies a low probability for charge transfer (eq 3a) between defects.

The electron transfer step is not required if one considers hydrogen atom migration between defects ${ }^{5}$ (see upper cycle in Figure 1)

$$
2\left[\mathrm{Li}^{+} \mathrm{O}^{-}\right] \mathrm{H} \rightarrow\left[\mathrm{Li}^{+} \mathrm{V}_{\mathrm{a}}^{-}\right]+\left[\mathrm{Li}^{+} \mathrm{O}^{-}\right]+\mathrm{H}_{2} \mathrm{O}(\mathrm{g})
$$

instead of proton migration. However, hydrogen atom interactions with the nondefective $\mathrm{MgO}$ surface are very weak, ${ }^{30-32}$ and at high temperatures desorption is expected instead of migration on the surface.

The above discussion of the Ito-Lunsford mechanism naturally leads to the following question: Is it possible to suggest a full cycle of catalytic surface reactions that (i) can proceed from only one $\left[\mathrm{Li}^{+} \mathrm{O}^{-}\right]$active site and (ii) does not require the removal of surface lattice oxygen? On the basis of these conditions, and assuming such types of surface reactions as molecular or dissociative adsorption of oxygen, hydrogen abstraction from methane, and water desorption, we can formally suggest that conversion of methane over $\left[\mathrm{Li}^{+} \mathrm{O}^{-}\right]$defects should proceed through several reaction intermediates with the general form

$$
\left[\mathrm{Li}^{+} \mathrm{O}^{-}\right] \mathrm{O}_{n} \mathrm{H}_{m} \quad(n=0,1,2 ; m=0,1,2)
$$

This gives rise to three questions which we will address in the remainder of this paper: (1) Which species from eq 7 are stable and can serve as reaction intermediates? (2) Can the stable species participate in thermodynamically allowable reactions with gas phase molecules? (3) Is it possible to construct closed catalytic cycles from these reactions? To answer the above

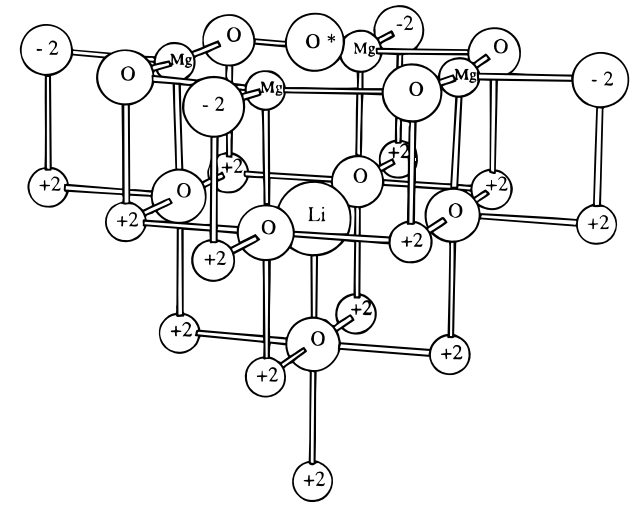

Figure 2. Optimized geometry for the $\left[\mathrm{Li}^{+} \mathrm{O}^{-}\right]$surface defect. This cluster is embedded in the field generated by 224 additional point charges (not shown).

questions, we have performed $a b$ initio calculations using an embedded cluster model of the $\left[\mathrm{Li}^{+} \mathrm{O}^{-}\right]$active site at the $\mathrm{MgO}$ (001) surface. This model and the computational techniques used are described in the next section.

\section{Computational Method}

The strategy employed in this work is to first optimize geometries for the surface defects of eq 7 as well as other relevant species. From calculated total energies of stable intermediates, we determine reaction energies for different possible catalytic cycles. This information can tell us about the relative importance of different reaction channels. Although information about transition states is required for a thorough characterization of reactions, we leave the identification of transition states for our future work.

The embedded cluster model used here is similar to that employed in our previous study. ${ }^{32}$ We used the cluster shown in Figure 2 to model adsorption at the $\left[\mathrm{Li}^{+} \mathrm{O}^{-}\right]$defect. We have placed the $\mathrm{Li}^{+}$ion in the second layer of the $\mathrm{MgO}(001)$ surface. This choice is somewhat arbitrary, and it would be interesting to investigate the dependence of results on position of the lithium impurity. However, as discussed above, we believe that the role of lithium is merely to stabilize the main reactive species $\mathrm{O}^{-}$; therefore, the impurity position is of secondary importance.

In the energy minimization procedures, all adsorbate atoms, the reactive surface oxygen (marked as $\mathrm{O} *$ in Figures 2 and 3), and its nearest magnesium neighbors were fully relaxed with no elements of symmetry assumed. Lithium was allowed to move normal to the surface, and all other ions were held fixed at ideal lattice positions. Several trial configurations were considered for each adsorbate of eq 7. Some optimized adsorbate structures are shown in Figure 3 where only the central part of the cluster is depicted.

Depending on multiplicity, geometry optimizations were performed by using either the restricted or restricted open-shell Hartree-Fock methods. For computational feasibility, ionic cores were approximated by Stevens-Basch-Krauss compact effective pseudopotentials (CEP). ${ }^{33}$ We used the standard valence CEP-31G** basis set on lithium, on the central oxygen atom, and on all adsorbed atoms. The CEP-31G basis set was used for nine oxygen ions nearest to the $\mathrm{Li}^{+}-\mathrm{O}^{*}$ pair. Oxygen ions marked as " -2 " in Figure 2 were modeled as point charges without basis functions. The CEP-4G basis set was placed on the four $\mathrm{Mg}$ ions at the surface, and for a better description of the interaction between these ions and their oxygen neighbors modeled as point charges, short-range classical repulsions ${ }^{34}$ between these centers were added to the total energy of the cluster. Without this repulsive potential, $\mathrm{Mg}$ ions would simply collapse on their point-charge neighbors. Other $\mathrm{Mg}$ ions in the 

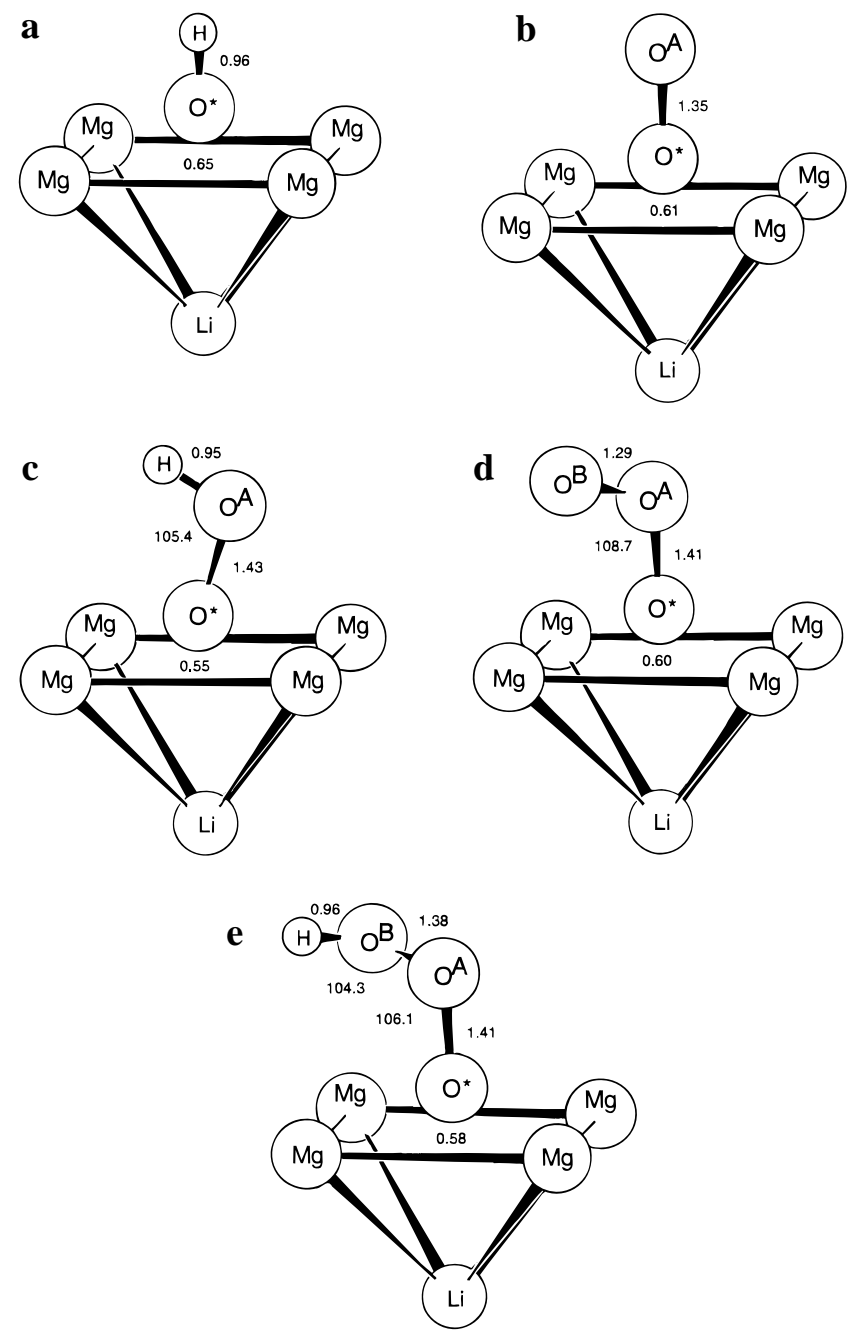

Figure 3. Optimized geometries of selected surface species. Only the central part of the cluster in Figure 2 is shown. Bond lengths and the height of the $\mathrm{O}^{*}$ atom above the surface are in angstroms; bond angles are in degrees. (a) $\left[\mathrm{Li}^{+} \mathrm{O}^{-}\right] \mathrm{H}$, (b) $\left[\mathrm{Li}^{+} \mathrm{O}^{-}\right] \mathrm{O}$, (c) $\left[\mathrm{Li}^{+} \mathrm{O}^{-}\right] \mathrm{OH}$, (d) $\left[\mathrm{Li}^{+} \mathrm{O}^{-}\right] \mathrm{O}_{2},(\mathrm{e})\left[\mathrm{Li}^{+} \mathrm{O}^{-}\right] \mathrm{O}_{2} \mathrm{H}$.

TABLE 1: Bond Energies (kcal/mol) for Some Gas Phase Molecules and Reaction Energy for Methane Conversion to Ethane (See Eq 5)

\begin{tabular}{lrrl}
\hline \multicolumn{1}{c}{ equation } & HF & MP2 & expt \\
\hline $\mathrm{O}_{2} \rightarrow \mathrm{O}+\mathrm{O}$ & 22 & 113 & $119.106 \pm 0.048^{a}$ \\
$\mathrm{H}_{2} \mathrm{O} \rightarrow \mathrm{OH}+\mathrm{H}$ & 89 & 119 & $119 \pm 1^{a}$ \\
$\mathrm{OH} \rightarrow \mathrm{O}+\mathrm{H}$ & 68 & 96 & $102.3 \pm 0.5^{a}$ \\
$\mathrm{CH}_{4} \rightarrow \mathrm{CH}_{3}+\mathrm{H}$ & 88 & 107 & $104 \pm 1^{a}$ \\
$\mathrm{C}_{2} \mathrm{H}_{6} \rightarrow \mathrm{CH}_{3}+\mathrm{CH}_{3}$ & 67 & 92 & $88 \pm 2^{a}$ \\
$4 \mathrm{CH}_{4}+\mathrm{O}_{2} \rightarrow 2 \mathrm{C}_{2} \mathrm{H}_{6}+2 \mathrm{H}_{2} \mathrm{O}$ & -74 & -73 & $-84.5^{b}$ \\
${ }^{a} D_{298}^{\circ}, \operatorname{ref} 48 .{ }^{b} \Delta \mathrm{ff}_{298}^{\circ}$, ref 48. & & \\
\end{tabular}

cluster (labeled “+2") were approximated by bare pseudopotentials without basis sets. We describe a surface anion vacancy by removing the central oxygen core while leaving its basis set in the vacancy. This is common practice when an accurate representation of the electron distribution in the $\mathrm{V}_{\mathrm{a}}{ }^{-}$ defect $\left(\mathrm{F}^{+}\right.$center $)$is required. ${ }^{28}$

Correlation energy was included by performing single-point second-order Møller-Plesset perturbation theory (MP2) calculations at Hartree-Fock optimized geometries. As an indication of the quality of our chosen correlation method, pseudopotential, and basis sets, we compare in Table 1 the calculated bond energies of relevant gas phase molecules with experimental data. Note the significant improvement of MP2 results as compared to Hartree-Fock calculations.
In order to represent the rest of the crystal, the cluster described above was embedded in the field generated by 224 lattice point charges of \pm 2 . For a better view of the active site, the entire system is not shown in Figure 2. It consisted of four stacked $8 \times 8$ layers resulting in an $8 \times 8 \times 4$ slab. This finite lattice has been shown to provide an accurate Madelung potential at the $(001)$ rock salt crystal surface. ${ }^{32}$

Although it is known that crystal polarization can have a significant effect on calculated energies of charged defects, ${ }^{23,35}$ our model does not allow for polarization in the lattice surrounding the $\left[\mathrm{Li}^{+} \mathrm{O}^{-}\right]$defect. Since most of the defects considered here are neutral, and we calculate relative energies rather than absolute values, we expect errors from such neglect of lattice polarization to be small.

All calculations were performed using the GAUSSIAN-92 computer code ${ }^{36}$ that was modified to include analytical first derivatives of interactions between ions in the quantum cluster and the lattice of point charges.

In characterizing the electronic structure of various surface defects, we present results for the electronic density of states (DOS). These DOS graphs were generated by Gaussian smoothing of orbital energy levels with the exponent of 440 hartree $^{-2}$. Although these graphs do not take into account electron correlation effects, DOS information can be useful for qualitative analysis of data collected in surface characterization experiments. ${ }^{37}$

\section{Results}

$\left[\mathbf{M g}^{2+} \mathbf{O}^{2-}\right]$. This cluster models the regular $\mathrm{MgO}(001)$ surface. Optimized positions of lattice ions do not deviate significantly from ideal lattice sites. $\mathrm{Mg}^{2+}$ surface ions move slightly toward the bulk, and oxygen relaxes away from the surface by $0.06 \AA$. Such small relaxations are in qualitative agreement with existing experimental data and other accurate calculations. ${ }^{27}$ This further supports the quality of our cluster model and computational methods. The calculated DOS is depicted by the solid line in Figure $4 \mathrm{a}$ and provides a base-line comparison to more complicated defect structures.

$\left[\mathbf{L i}^{+} \mathbf{O}^{-}\right]$. In our calculations, the electronic hole is well localized on the surface $\mathrm{O}^{*}$ oxygen atom. Almost $98 \%$ of the electron spin density is concentrated on the $\mathrm{p}_{z}$ orbital of this atom. The optimized geometry for a lithium-trapped hole defect is shown in Figure 2. The $\mathrm{O}^{*}$ atom relaxes away from the surface by $0.35 \AA$, and the $\mathrm{Li}^{+}$ion moves toward the bulk so that the $\mathrm{Li}^{+}-\mathrm{O}^{*}$ spacing is increased by $0.53 \AA$ with respect to the $\left[\mathrm{Mg}^{2+} \mathrm{O}^{2-}\right]$ cluster. This agrees qualitatively with both theoretical and experimental studies of bulk defects, ${ }^{23,38,39}$ although a contraction of the defect bond distance has also been calculated. ${ }^{24}$ The DOS for the $\left[\mathrm{Li}^{+} \mathrm{O}^{-}\right]$defect is compared with that of the regular $\mathrm{MgO}(001)$ surface in Figure 4a. Due to the reduced electrostatic potential on oxygen ions close to the $\mathrm{Li}^{+}$ impurity, their energy levels are higher. This causes the broadening of the "valence bands" clearly seen in Figure 4a. A half-filled $\mathrm{O}_{\mathrm{p}}^{*}$ level splits into the band gap, and a shoulder appears on the lower part of the valence band due to $\mathrm{O}_{\mathrm{p}_{x y}}^{*}$ levels.

$\left[\mathrm{Li}^{+} \mathrm{O}^{2-}\right]$ and $\left[\mathrm{Li}^{+} \mathbf{V}_{\mathbf{a}}\right]$. In comparison to the $\left[\mathrm{Mg}^{2+} \mathrm{O}^{2-}\right]$ structure, the $\mathrm{O}^{*}$ atom of a closed-shell $\left[\mathrm{Li}^{+} \mathrm{O}^{2-}\right]$ defect moves to a height of $0.33 \AA$ above the surface, and the cation is displaced in the direction of the bulk. This results in an $\mathrm{Li}^{+}-$ $\mathrm{O}^{*}$ spacing that is increased by $0.40 \AA$ over the $\left[\mathrm{Mg}^{2+} \mathrm{O}^{2-}\right]$ cluster. The major differences in the DOS of $\left[\mathrm{Li}^{+} \mathrm{O}^{2-}\right]$ with respect to $\left[\mathrm{Mg}^{2+} \mathrm{O}^{2-}\right]$ are a band broadening and a uniform shift to higher energies due to the reduced charge of the cation. In contrast, the DOS structure of the positively charged $\left[\mathrm{Li}^{+} \mathrm{V}_{\mathrm{a}}\right]$ is shifted to lower energies in comparison to $\left[\mathrm{Mg}^{2+} \mathrm{O}^{2-}\right]$. 

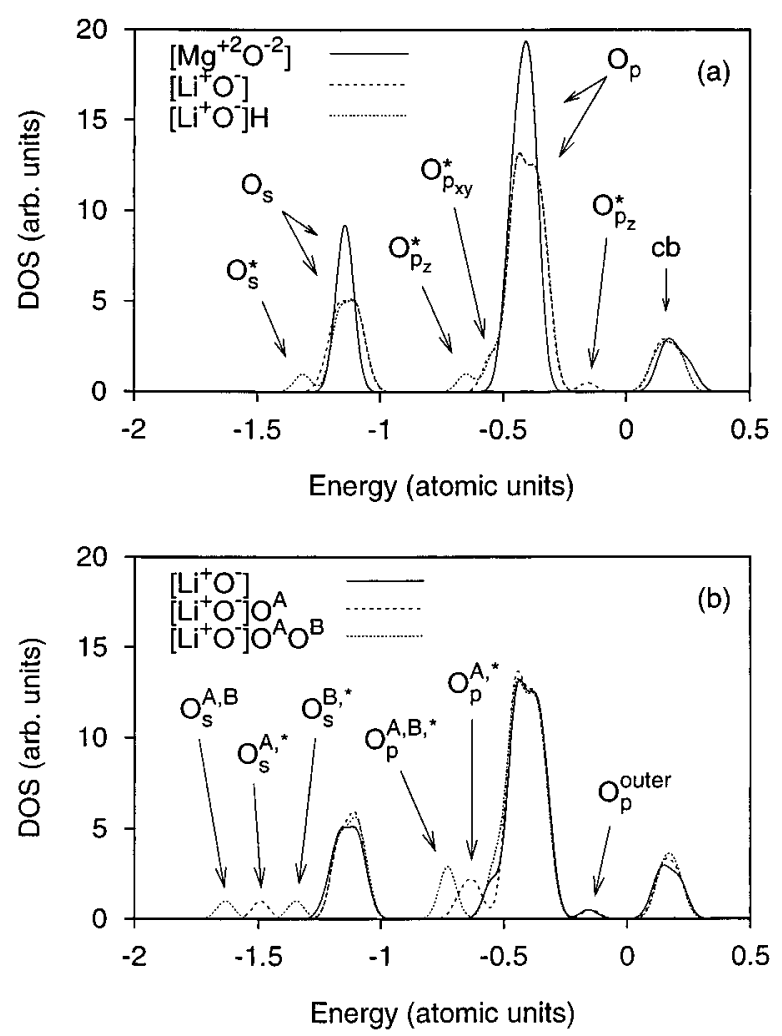

Figure 4. Calculated DOS. For atom labeling; see Figure 3. The conduction band states are labeled "cb", and "outer" refers to the single oxygen atom $\left(\mathrm{O}^{*}, \mathrm{O}^{\mathrm{A}}\right.$, or $\left.\mathrm{O}^{\mathrm{B}}\right)$ that is farthest away from $\mathrm{Li}^{+}$. (a) Comparison of the $\mathrm{MgO}(001)$ surface (solid line) with the $\left[\mathrm{Li}^{+} \mathrm{O}^{-}\right]$ (dashed line) and the $\left[\mathrm{Li}^{+} \mathrm{O}^{-}\right] \mathrm{H}$ (dotted line) defects. (b) Comparison of the various stages of oxygen chemisorption at the $\left[\mathrm{Li}^{+} \mathrm{O}^{-}\right]$defect.

$\left[\mathbf{L i}^{+} \mathbf{V}_{\mathbf{a}}^{-}\right]$. An electron trapped in an oxygen vacancy $\left(\mathrm{V}_{\mathrm{a}}^{-}\right)$ is analogous to an $\mathrm{F}^{+}$center. Our calculations show that four neighboring surface $\mathrm{Mg}^{2+}$ ions relax laterally outward by an average of $0.09 \AA$. This is consistent with other theoretical studies. ${ }^{28,40}$ We found the position of the defect level to be about $7.6 \mathrm{eV}$ above the top of the valence band. This is much higher than that reported in refs 28 and 40 for $^{+}$centers because $\mathrm{Li}^{+}$substituting for $\mathrm{Mg}^{2+}$ decreases the electrostatic potential in the vacancy by several electronvolts. For the same reason, the energy required to remove oxygen from the $\left[\mathrm{Li}^{+} \mathrm{O}^{-}\right]$defect (118 kcal/mol in our calculations) to form $\left[\mathrm{Li}^{+} \mathrm{V}_{\mathrm{a}}{ }^{-}\right]$and $\mathrm{O}(\mathrm{g})$ is lower than the energy to remove an oxygen atom from the ideal $\mathrm{MgO}(001)$ surface. Theoretical estimates for the latter range from 177 to $229 \mathrm{kcal} / \mathrm{mol}^{27-29}$

$\left[\mathbf{L i}^{+} \mathbf{O}^{-}\right] \mathbf{H}$. Properties of $\mathrm{OH}^{-}$ions associated with bulk $\mathrm{Li}^{+}$ impurities are documented in literature. ${ }^{41}$ Shown in Figure 3a is the relaxed geometry of surface $\left[\mathrm{Li}^{+} \mathrm{O}^{-}\right] \mathrm{H}$. Our calculated $\mathrm{O}^{*}-\mathrm{H}$ bond distance of $0.96 \AA$ agrees exactly with the $\mathrm{OH}^{-}$ gas phase value. ${ }^{42}$ In Figure $4 \mathrm{a}$ we illustrate the effects of adsorbed hydrogen on the density of states of the $\left[\mathrm{Li}^{+} \mathrm{O}^{-}\right]$defect. The defect level in the band gap is removed, and additional peaks appear on the lower energy side of both $\mathrm{O}_{\mathrm{s}}$ and $\mathrm{O}_{\mathrm{p}}$ valence bands. The hydrogen affinity of $121 \mathrm{kcal} / \mathrm{mol}$ (see Table 2) is larger than the $\mathrm{C}-\mathrm{H}$ bond energy in methane, which is 107 $\mathrm{kcal} / \mathrm{mol}$ in our calculations (see Table 1). This confirms the role of surface $\left[\mathrm{Li}^{+} \mathrm{O}^{-}\right]$defects as active sites for hydrogen abstraction from methane.

$\left[\mathrm{Li}^{+} \mathrm{O}^{-}\right] \mathrm{O}$ and $\left[\mathrm{Li}^{+} \mathrm{O}^{-}\right] \mathrm{OH}$. Atomic oxygen chemisorbed to the $\left[\mathrm{Li}^{+} \mathrm{O}^{-}\right]$defect yields a surface species similar to superoxide ion, $\mathrm{O}_{2}^{-}$. Our calculated bond length of $1.35 \AA$ for $\mathrm{O}^{*}-\mathrm{O}^{\mathrm{A}}$ (see Figure $3 \mathrm{~b}$ ) is very close to the $1.34 \AA$ reported for superoxide ion in the gas phase. ${ }^{42}$ In comparison to $\left[\mathrm{Li}^{+} \mathrm{O}^{-}\right]$, the DOS of $\left[\mathrm{Li}^{+} \mathrm{O}^{-}\right] \mathrm{O}$ (Figure $4 \mathrm{~b}$ ) has additional features in the lower energy parts of both $\mathrm{O}_{\mathrm{s}}$ and $\mathrm{O}_{\mathrm{p}}$ valence bands. They
TABLE 2: Calculated MP2 Binding Energies (kcal/mol) for Adsorbates Related to the Oxidative Coupling of Methane Over $\mathrm{Li} / \mathrm{MgO}$ and Results for Similar Systems Taken from Literature

\begin{tabular}{cccc}
\hline surface & adsorbate & binding energy & results from lit. \\
\hline$\left[\mathrm{Li}^{+} \mathrm{V}_{\mathrm{a}}^{-}\right]$ & $\mathrm{O}$ & 118 & $225^{a}$ \\
{$\left[\mathrm{Li}^{+} \mathrm{O}^{-}\right]$} & $\mathrm{H}$ & 121 & $107^{b}$ \\
{$\left[\mathrm{Li}^{+} \mathrm{O}^{-}\right]$} & $\mathrm{O}$ & 54 & $40^{c}$ \\
{$\left[\mathrm{Li}^{+} \mathrm{O}^{-}\right]$} & $\mathrm{O}_{2}$ & -9 & \\
{$\left[\mathrm{Li}^{+} \mathrm{O}^{-}\right]$} & $\mathrm{OH}$ & 51 & $56^{d}$ \\
{$\left[\mathrm{Li}^{+} \mathrm{O}^{-}\right]$} & $\mathrm{O}_{2} \mathrm{H}$ & 40 & \\
{$\left[\mathrm{Li}^{+} \mathrm{O}^{-}\right] \mathrm{O}$} & $\mathrm{H}$ & 93 & $63^{e}$ \\
{$\left[\mathrm{Li}^{+} \mathrm{O}^{-}\right] \mathrm{O}$} & $\mathrm{O}$ & 50 & $58^{f}$ \\
{$\left[\mathrm{Li}^{+} \mathrm{O}^{-}\right] \mathrm{O}$} & $\mathrm{OH}$ & 42 & \\
{$\left[\mathrm{Li}^{+} \mathrm{O}^{-}\right] \mathrm{O}_{2}$} & $\mathrm{H}$ & 88 &
\end{tabular}

${ }^{a}$ Energy required to remove an $\mathrm{O}$ atom from the $\mathrm{MgO}(001)$ surface lattice site in ref 27 . Other estimates include 177 from ref 28 and 229 from ref 29. ${ }^{b}$ From ref $15 .{ }^{c}$ For oxygen atom adsorption to $\mathrm{O}^{-}$on $\mathrm{MgO}$ in ref 49. ${ }^{d} \Delta E$ for $\mathrm{O}_{2} \mathrm{H}^{-}(\mathrm{g}) \rightarrow \mathrm{O}^{-}(\mathrm{g})+\mathrm{OH}(\mathrm{g})$ determined using the electron affinities of $\mathrm{O}_{2} \mathrm{H}$ and $\mathrm{O}$ from ref 50 , calculated $\mathrm{O}_{2}-\mathrm{H}$ bond energy from ref 51, and experimental bond energies of $\mathrm{O}_{2}$ and $\mathrm{OH}$ from ref 48. ${ }^{e} \Delta E$ for $\mathrm{O}_{2} \mathrm{H}^{-}(\mathrm{g}) \rightarrow \mathrm{O}_{2}{ }^{-}(\mathrm{g})+\mathrm{H}(\mathrm{g})$ determined using the electron affinities of $\mathrm{O}_{2} \mathrm{H}$ and $\mathrm{O}_{2}$ from ref 50 and the calculated $\mathrm{O}_{2}-\mathrm{H}$ bond energy from ref 51. ${ }^{f} \Delta E$ for $\mathrm{O}_{3}{ }^{-}(\mathrm{g}) \rightarrow \mathrm{O}_{2}{ }^{-}(\mathrm{g})+\mathrm{O}(\mathrm{g})$ determined using the calculated atomization energy of $\mathrm{O}_{3}{ }^{-}$from ref 52 and the $\mathrm{O}_{2}^{-}$bond energy taken from ref 42 .

are associated with $\mathrm{O}^{*}$ and $\mathrm{O}^{\mathrm{A}}$ oxygen atoms. The half-filled band gap state produced by the surface superoxide ion lies very close to that of the $\left[\mathrm{Li}^{+} \mathrm{O}^{-}\right]$defect. However, in the former case, this state and the maximum of the spin density distribution are associated with the adsorbed (outer) oxygen $\mathrm{O}^{\mathrm{A}}$. This indicates that adsorbed oxygen is now the reactive center. We have found a large hydrogen affinity of $\left[\mathrm{Li}^{+} \mathrm{O}^{-}\right] \mathrm{O}(93 \mathrm{kcal} /$ mol, see Table 2) and a stable configuration of the diamagnetic $\left[\mathrm{Li}^{+} \mathrm{O}^{-}\right] \mathrm{OH}$ defect (Figure $3 \mathrm{c}$ ) in our calculations. This agrees with experimental evidence that superoxide ion can be stable on the surface of $\mathrm{MgO}$ crystals and abstract hydrogen from methane. ${ }^{43}$ Similar to $\left[\mathrm{Li}^{+} \mathrm{O}^{-}\right] \mathrm{H}$, addition of hydrogen to superoxide results in removal of the band gap state and a splitting of the feature in the lower energy part of the $\mathrm{O}_{p}$ band into two peaks.

$\left[\mathrm{Li}^{+} \mathrm{O}^{-}\right] \mathrm{O}_{2}$ and $\left[\mathrm{Li}^{+} \mathrm{O}^{-}\right] \mathrm{O}_{2} \mathrm{H}$. In studying adsorption of molecular oxygen at the $\left[\mathrm{Li}^{+} \mathrm{O}^{-}\right]$site, we found a local minimum corresponding to the paramagnetic $\left[\mathrm{Li}^{+} \mathrm{O}^{-}\right] \mathrm{O}_{2}$ species (Figure 3d) resembling an ozonide ion. In this metastable state, molecular oxygen has a negative binding energy $(-9 \mathrm{kcal} / \mathrm{mol}$, see Table 2) to the surface. Ozonide ions have been experimentally detected on the surface of $\mathrm{MgO}$ at temperatures below $150{ }^{\circ} \mathrm{C} .44$ Similar to both $\left[\mathrm{Li}^{+} \mathrm{O}^{-}\right]$and $\left[\mathrm{Li}^{+} \mathrm{O}^{-}\right] \mathrm{O}$ defects, adsorbed diatomic oxygen gives rise to an electronic state in the band gap, and the related spin density is concentrated on the outermost oxygen atom $\left(\mathrm{O}^{\mathrm{B}}\right)$. Additional features appear below the $\mathrm{O}_{\mathrm{s}}$ and $\mathrm{O}_{\mathrm{p}}$ valence bands as shown in Figure 4b. The effect of hydrogen adsorption to this system is similar to that discussed above for the $\left[\mathrm{Li}^{+} \mathrm{O}^{-}\right] \mathrm{O}$ defect. A singlet state $\left[\mathrm{Li}^{+} \mathrm{O}^{-}\right] \mathrm{O}_{2} \mathrm{H}$ defect is produced which cannot be detected using ESR techniques. Our calculated value for the hydrogen affinity of $\left[\mathrm{Li}^{+} \mathrm{O}^{-}\right] \mathrm{O}_{2}$ is $88 \mathrm{kcal} / \mathrm{mol}$. This indicates a substantial reactivity of this defect in agreement with experimental observations for ozonide ion on the $\mathrm{MgO}$ surface. ${ }^{44}$

$\left[\mathrm{Li}^{+} \mathrm{O}^{-}\right] \mathrm{H}_{2},\left[\mathrm{Li}^{+} \mathrm{O}^{-}\right] \mathrm{OH}_{2}$, and $\left[\mathrm{Li}^{+} \mathrm{O}^{-}\right] \mathrm{O}_{2} \mathrm{H}_{2}$. We were not able to find stable configurations for hydrogen, water, and hydrogen peroxide adsorbed at the $\left[\mathrm{Li}^{+} \mathrm{O}^{-}\right]$defect. All initial geometries for adsorbed molecular hydrogen dissociated into $\left[\mathrm{Li}^{+} \mathrm{O}^{-}\right] \mathrm{H}$ and gas phase atomic hydrogen. It seems that the only way to bind atomic hydrogen to $\left[\mathrm{Li}^{+} \mathrm{O}^{-}\right] \mathrm{H}$ is to first remove the $\mathrm{OH}$ group sufficiently far from the surface. This results in a gas phase water molecule and the $\left[\mathrm{Li}^{+} \mathrm{V}_{\mathrm{a}}{ }^{-}\right]$defect on the surface as in eq 6 of the Ito-Lunsford mechanism. 
TABLE 3: Calculated Reaction Energies (kcal/mol) for Processes Related to the Ito-Lunsford Mechanism ${ }^{a}$

\begin{tabular}{llr}
\hline eq no. & \multicolumn{1}{c}{ reaction } & $\Delta E^{\mathrm{MP} 2}$ \\
\hline (1) & $2\left[\mathrm{Li}^{+} \mathrm{O}^{-}\right]+2 \mathrm{CH}_{4}(\mathrm{~g}) \rightarrow 2\left[\mathrm{Li}^{+} \mathrm{O}^{-}\right] \mathrm{H}+2 \mathrm{CH}_{3}(\mathrm{~g})$ & -28 \\
$(3)$ & $2\left[\mathrm{Li}^{+} \mathrm{O}^{-}\right] \mathrm{H} \rightarrow\left[\mathrm{Li}^{+} \mathrm{O}^{2-}\right]+\left[\mathrm{Li}^{+} \mathrm{V}_{\mathrm{a}}\right]+\mathrm{H}_{2} \mathrm{O}(\mathrm{g})$ & +162 \\
$(3 \mathrm{a})$ & {$\left[\mathrm{Li}^{+} \mathrm{O}^{2-}\right]+\left[\mathrm{Li}^{+} \mathrm{V}_{\mathrm{a}}\right] \rightarrow\left[\mathrm{Li}^{+} \mathrm{O}^{-}\right]+\left[\mathrm{Li}^{+} \mathrm{V}_{\mathrm{a}}^{-}\right]$} & -17 \\
$(4)$ & {$\left[\mathrm{Li}^{+} \mathrm{V}_{\mathrm{a}}^{-}\right]+\mathrm{O}_{2}(\mathrm{~g}) \rightarrow\left[\mathrm{Li}^{+} \mathrm{O}^{-}\right]+\mathrm{O}(\mathrm{g})$} & -5 \\
$(4 \mathrm{a})$ & {$\left[\mathrm{Li}^{+} \mathrm{V}_{\mathrm{a}}^{-}\right]+\mathrm{O}(\mathrm{g}) \rightarrow\left[\mathrm{Li}^{+} \mathrm{O}^{-}\right]$} & -118 \\
$(6)$ & $2\left[\mathrm{Li}^{+} \mathrm{O}^{-}\right] \mathrm{H} \rightarrow\left[\mathrm{Li}^{+} \mathrm{V}_{\mathrm{a}}^{-}\right]+\left[\mathrm{Li}^{+} \mathrm{O}^{-}\right]+\mathrm{H}_{2} \mathrm{O}(\mathrm{g})$ & +145 \\
$(8)$ & {$\left[\mathrm{Li}^{+} \mathrm{O}^{-}\right] \mathrm{H}+\mathrm{H}(\mathrm{g}) \rightarrow\left[\mathrm{Li}^{+} \mathrm{V}_{\mathrm{a}}^{-}\right]+\mathrm{H}_{2} \mathrm{O}(\mathrm{g})$} & +24
\end{tabular}
5 a.

${ }^{a}$ A cycle composed of reactions 1-4a is shown graphically in Figure

Although the endothermicity of the reaction

$$
\left[\mathrm{Li}^{+} \mathrm{O}^{-}\right] \mathrm{H}+\mathrm{H}(\mathrm{g}) \rightarrow\left[\mathrm{Li}^{+} \mathrm{V}_{\mathrm{a}}^{-}\right]+\mathrm{H}_{2} \mathrm{O}(\mathrm{g})
$$

is only $24 \mathrm{kcal} / \mathrm{mol}$, it most likely has a large activation barrier. Although we have not found a stable structure for $\left[\mathrm{Li}^{+} \mathrm{O}^{-}\right] \mathrm{OH}_{2}$, our results suggest that water can either form a weakly bound complex with the surface $\left[\mathrm{Li}^{+} \mathrm{O}^{-}\right]$defect or undergo dissociation into gas phase $\mathrm{OH}$ and an adsorbed hydrogen atom. ${ }^{45}$ We found that, depending on initial geometry, adsorbed $\mathrm{O}_{2} \mathrm{H}_{2}$ dissociates according to one of the following schemes

$$
\begin{aligned}
{\left[\mathrm{Li}^{+} \mathrm{O}^{-}\right] \mathrm{OHOH} } & \rightarrow\left[\mathrm{Li}^{+} \mathrm{O}^{-}\right] \mathrm{OH}+\mathrm{OH}(\mathrm{g}) \\
{\left[\mathrm{Li}^{+} \mathrm{O}^{-}\right] \mathrm{OOH}_{2} } & \rightarrow\left[\mathrm{Li}^{+} \mathrm{O}^{-}\right] \mathrm{O}+\mathrm{H}_{2} \mathrm{O}(\mathrm{g})
\end{aligned}
$$

\section{Discussion}

In our calculations, the overall conversion shown in eq 5 is exothermic by $73 \mathrm{kcal} / \mathrm{mol}$. This conversion can be achieved through several different cycles of surface reactions. On the basis of computed energies of the stable surface reaction intermediates presented in the previous section, we can construct energy profiles for these catalytic cycles.

Reaction energies for the surface processes that compose the Ito-Lunsford cycle appear in Table 3, and the proton transfer channel is diagrammed in Figure 5a. As already mentioned in the Introduction, oxygen removal from the lattice site requires a large amount of energy; our calculations yield 162 and 145 $\mathrm{kcal} / \mathrm{mol}$ for reactions 3 and 6 , respectively. These are well in excess of the experimentally determined activation energy for methane conversion, which is about $55 \mathrm{kcal} / \mathrm{mol} .^{5,46}$

Considering the results of our calculations, we have assembled in Figure 6 the collection of possible catalytic cycles that satisfy conditions (i) and (ii) from the introduction. The hydrogen abstraction reaction

$$
\begin{array}{r}
{\left[\mathrm{Li}^{+} \mathrm{O}^{-}\right]+\mathrm{CH}_{4}(\mathrm{~g}) \rightarrow\left[\mathrm{Li}^{+} \mathrm{O}^{-}\right] \mathrm{H}+\mathrm{CH}_{3}(\mathrm{~g})} \\
\Delta E=-14 \mathrm{kcal} / \mathrm{mol}
\end{array}
$$

is exothermic, but all other surface reactions shown in Figure 6 with thin arrows, and listed in the lower portion of Table 4, have positive reaction energies in excess of $40 \mathrm{kcal} / \mathrm{mol}$. Therefore, we focus our discussion on the cycle indicated by bold arrows in Figure 6. This cycle begins with adsorption of molecular oxygen on the $\left[\mathrm{Li}^{+} \mathrm{O}^{-}\right]$defect, resulting in the formation of a surface ozonide ion (eq 10 of Table 4). This species abstracts hydrogen from methane forming another stable intermediate $\left[\mathrm{Li}^{+} \mathrm{O}^{-}\right] \mathrm{O}_{2} \mathrm{H}$, which, in its turn, reacts with methane to form the $\left[\mathrm{Li}^{+} \mathrm{O}^{-}\right] \mathrm{O}$ defect, a $\mathrm{CH}_{3}$ radical, and a water molecule (see eq 12 of Table 4). As discussed in the previous section, $\left[\mathrm{Li}^{+} \mathrm{O}^{-}\right] \mathrm{O}$ has a significant hydrogen affinity; therefore, it may abstract hydrogen from methane (eq 13 of Table 4) and then participate in a second reaction with methane to form water and restore the active site (eq 14 of Table 4). Positive energies

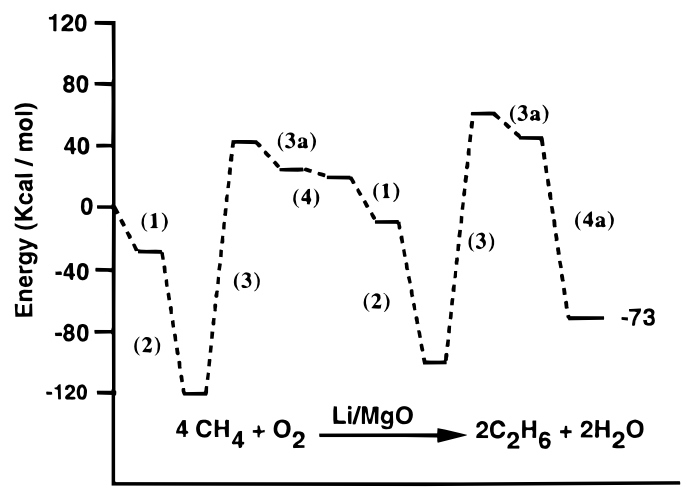

Reaction Coordinate

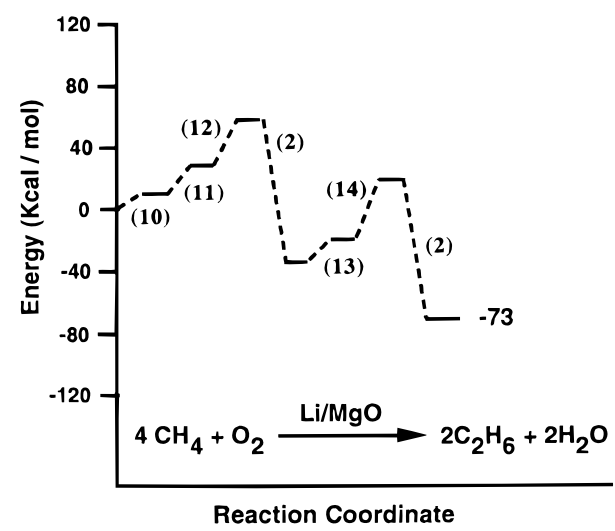

Figure 5. Calculated energy profiles for the methane conversion given by eq 5 . Reaction numbers are given in parentheses. (a, top) Two iterations of the Ito-Lunsford cycle with proton transfer (see Table 3 for reaction energies). (b, bottom) Our proposed single site cycle indicated by bold arrows in Figure 6 (see Table 4 for reaction energies).

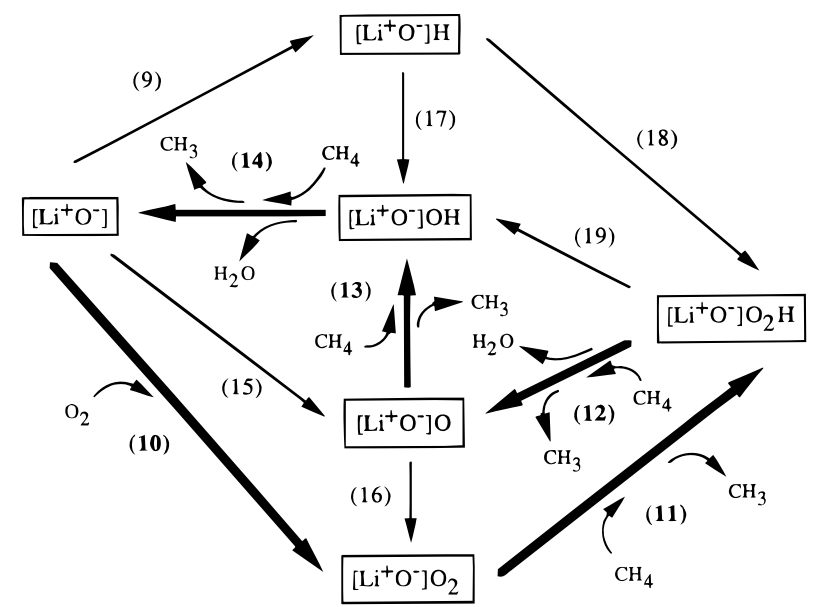

Figure 6. Possible catalytic cycles that involve only one $\left[\mathrm{Li}^{+} \mathrm{O}^{-}\right]$ reactive site. All reaction energies are given in Table 4 . The cycle shown by bold arrows is discussed in the text and illustrated in the energy profile of Figure $5 \mathrm{~b}$.

of surface reactions in Table 4 are compensated by exothermic coupling of gas phase methyl radicals (reaction 2).

Since the cycle indicated by bold arrows in Figure 6 leads to the overall conversion given in eq 5 , it can be conveniently compared with a 2-fold iteration of the Ito-Lunsford mechanism. In our proposed cycle, the largest endothermicities (14$39 \mathrm{kcal} / \mathrm{mol}$ ) are for hydrogen abstraction steps (see Figure $5 \mathrm{~b}$ ). Although we have no information about the reaction barriers, these calculated energy changes suggest that hydrogen abstraction is likely to be the rate-limiting step in our mechanism. This is qualitatively consistent with experimental evidence discussed in the Introduction and differs from the Ito-Lunsford mecha- 
TABLE 4: Calculated Reaction Energies (kcal/mol) for Processes Shown in Figure $6^{a}$

\begin{tabular}{rlr}
\hline \multicolumn{1}{c}{ eq no. } & \multicolumn{1}{c}{ reaction } & $\Delta E^{\mathrm{MP} 2}$ \\
\hline$(10)$ & {$\left[\mathrm{Li}^{+} \mathrm{O}^{-}\right]+\mathrm{O}_{2}(\mathrm{~g}) \rightarrow\left[\mathrm{Li}^{+} \mathrm{O}^{-}\right] \mathrm{O}_{2}$} & +9 \\
$(11)$ & {$\left[\mathrm{Li}^{+} \mathrm{O}^{-}\right] \mathrm{O}_{2}+\mathrm{CH}_{4}(\mathrm{~g}) \rightarrow\left[\mathrm{Li}^{+} \mathrm{O}^{-}\right] \mathrm{O}_{2} \mathrm{H}+\mathrm{CH}_{3}(\mathrm{~g})$} & +19 \\
$(12)$ & {$\left[\mathrm{Li}^{+} \mathrm{O}^{-}\right] \mathrm{O}_{2} \mathrm{H}+\mathrm{CH}_{4}(\mathrm{~g}) \rightarrow\left[\mathrm{Li}^{+} \mathrm{O}^{-}\right] \mathrm{O}+\mathrm{H}_{2} \mathrm{O}(\mathrm{g})+\mathrm{CH}_{3}(\mathrm{~g})$} & +30 \\
$(13)$ & {$\left[\mathrm{Li}^{+} \mathrm{O}^{-}\right] \mathrm{O}+\mathrm{CH}_{4}(\mathrm{~g}) \rightarrow\left[\mathrm{Li}^{+} \mathrm{O}^{-}\right] \mathrm{OH}+\mathrm{CH}_{3}(\mathrm{~g})$} & +14 \\
$(14)$ & {$\left[\mathrm{Li}^{+} \mathrm{O}^{-}\right] \mathrm{OH}+\mathrm{CH}_{4}(\mathrm{~g}) \rightarrow\left[\mathrm{Li}^{+} \mathrm{O}^{-}\right]+\mathrm{H}_{2} \mathrm{O}(\mathrm{g})+\mathrm{CH}_{3}(\mathrm{~g})$} & +39 \\
$(9)$ & {$\left[\mathrm{Li}^{+} \mathrm{O}^{-}\right]+\mathrm{CH}_{4}(\mathrm{~g}) \rightarrow\left[\mathrm{Li}^{+} \mathrm{O}^{-}\right] \mathrm{H}+\mathrm{CH}_{3}(\mathrm{~g})$} & -14 \\
$(15)$ & {$\left[\mathrm{Li}^{+} \mathrm{O}^{-}\right]+\mathrm{O}_{2}(\mathrm{~g}) \rightarrow\left[\mathrm{Li}^{+} \mathrm{O}^{-}\right] \mathrm{O}+\mathrm{O}(\mathrm{g})$} & +59 \\
$(16)$ & {$\left[\mathrm{Li}^{+} \mathrm{O}^{-}\right] \mathrm{O}+\mathrm{O}_{2}(\mathrm{~g}) \rightarrow\left[\mathrm{Li}^{+} \mathrm{O}^{-}\right] \mathrm{O}_{2}+\mathrm{O}(\mathrm{g})$} & +63 \\
$(17)$ & {$\left[\mathrm{Li}^{+} \mathrm{O}^{-}\right] \mathrm{H}+\mathrm{O}_{2}(\mathrm{~g}) \rightarrow\left[\mathrm{Li}^{+} \mathrm{O}^{-}\right] \mathrm{OH}+\mathrm{O}(\mathrm{g})$} & +87 \\
$(18)$ & {$\left[\mathrm{Li}^{+} \mathrm{O}^{-}\right] \mathrm{H}+\mathrm{O}_{2}(\mathrm{~g}) \rightarrow\left[\mathrm{Li}^{+} \mathrm{O}^{-}\right] \mathrm{O}_{2} \mathrm{H}$} & +42 \\
$(19)$ & {$\left[\mathrm{Li}^{+} \mathrm{O}^{-}\right] \mathrm{O}_{2} \mathrm{H}+\mathrm{CH}_{4}(\mathrm{~g}) \rightarrow\left[\mathrm{Li}^{+} \mathrm{O}^{-}\right] \mathrm{OH}+\mathrm{OH}(\mathrm{g})+\mathrm{CH}_{3}(\mathrm{~g})$} & +56
\end{tabular}

${ }^{a}$ Our proposed cycle for the oxidative coupling of methane over $\mathrm{Li} / \mathrm{MgO}$ is composed of reactions $10-14$. Its energy profile is shown in Figure $5 b$.

nism where the lattice oxygen removal step is most likely to be rate limiting.

In calculating energies for reactions $15-17$ in Table 4 , we assumed that an oxygen atom is released into the gas phase. Adsorption of this species on the $\mathrm{MgO}$ surface may result in an energy gain of about $40 \mathrm{kcal} / \mathrm{mol},{ }^{47}$ thus substantially reducing the endothermicities of reactions $15-17$ and making additional catalytic channels energetically comparable with the cycle discussed above. Although a complicated dynamical chemical equilibrium exists at the elevated temperatures required for operation of the $\mathrm{Li} / \mathrm{MgO}$ catalyst, we believe that the singlesite catalytic cycle presented here is credible and perhaps competes with the Ito-Lunsford cycle for production of methyl radicals at the catalyst surface.

\section{Conclusions}

Using an $a b$ initio embedded cluster model, we have systematically examined the structure and stability of various defects on the Li-doped $\mathrm{MgO}(001)$ surface. From these results, we propose a new catalytic cycle for the oxidative coupling of methane that involves only one defect site. This newly proposed cycle differs significantly from the existing Ito-Lunsford mechanism which requires exchange of a proton and an electron between two distant defect sites and the energetically unfavorable process of lattice oxygen removal. Our calculations predict that, in addition to the well-known $\left[\mathrm{Li}^{+} \mathrm{O}^{-}\right]$defect, other surface species such as $\left[\mathrm{Li}^{+} \mathrm{O}^{-}\right] \mathrm{O}_{2}$ and $\left[\mathrm{Li}^{+} \mathrm{O}^{-}\right] \mathrm{O}$ may abstract hydrogen from methane. Our proposed catalytic cycle is supported by experimental results regarding the rate-limiting step and activation energy for methane conversion to ethane.

Acknowledgment. This research was supported by the University of Utah and the National Science Foundation through a NSF Young Investigator Award to T.N.T.

\section{References and Notes}

(1) Lunsford, J. H. Catal. Today 1990, 6, 235.

(2) Crabtree, R. H. Chem. Rev. 1995, 95, 987.

(3) Lunsford, J. H. Angew. Chem., Int. Ed. Engl. 1995, 34, 970.

(4) Hutchings, G. J.; Woodhouse, J. R.; Scurrell, M. S. J. Chem. Soc., Faraday Trans. 1 1989, 85, 2507.

(5) Ito, T.; Wang, J.-X.; Lin, C.-H.; Lunsford, J. H. J. Am. Chem. Soc. 1985, 107,5062 .

(6) Keller, G. E.; Bhasin, M. M. J. Catal. 1982, 73, 9.

(7) Grimes, R. W., Catlow, C. R. A., Shluger, A. L., Eds. Quantum Mechanical Cluster Calculations in Solid State Studies; World Scientific: Singapore, 1992.

(8) Cant, N. W.; Lukey, C. A.; Nelson, P. F.; Tyler, R. J. J. Chem. Soc., Chem. Commun. 1988, 766.
(9) Amorebieta, V. T.; Colussi, A. J. J. Phys. Chem. 1988, 92, 4576.

(10) Campbell, K. D.; Lunsford, J. H. J. Phys. Chem. 1988, 92, 5792.

(11) Wu, M.-C.; Truong, C. M.; Coulter, K.; Goodman, D. W. J. Am. Chem. Soc. 1992, 114, 7565 .

(12) Wu, M.-C.; Truong, C. M.; Coulter, K.; Goodman, D. W. J. Catal. 1993, 140,344

(13) Shluger, A. L.; Grimes, R. W.; Catlow, C. R. A.; Itoh, N. J. Phys.: Condens. Matter 1991, 3, 8027.

(14) Pope, S. A.; Guest, M. F.; Hillier, I. H.; Colbourn, E. A.; Mackrodt, W. C.; Kendrick, J. Phys. Rev. B 1983, 28, 2191.

(15) Børve, K. J.; Pettersson, L. G. M. J. Phys. Chem. 1991, 95, 7401

(16) Børve, K. J. J. Chem. Phys. 1991, 95, 4626.

(17) Kobayashi, H.; Salahub, D. R.; Ito, T. J. Phys. Chem. 1994, 98, 5487.

(18) Shluger, A. L.; Gale, J. D.; Catlow, C. R. A. J. Phys. Chem. 1992, 96, 10389. 701.

(19) Anpo, M.; Doi, T.; Matsuura, I.; Sunamoto, M. Chem. Lett. 1988

(20) Wang, J.-X.; Lunsford, J. H. J. Phys. Chem. 1986, 90, 5883.

(21) Abraham, M. M.; Chen, Y.; Boatner, L. A.; Reynolds, R. W. Phys. Rev. Lett. 1976, 37, 849.

(22) Chen, Y.; Tohver, H. T.; Narayan, J.; Abraham, M. M. Phys. Rev. $B$ 1977, 16, 5535 .

(23) Shluger, A. L.; Kotomin, E. A.; Kantorovich, L. N. J. Phys. C: Solid State Phys. 1986, 19, 4183.

(24) Zuo, J.; Pandey, R.; Kunz, A. B. Phys. Rev. B: Condens. Matter 1991, 44, 7187.

(25) Foot, J. D.; Colbourn, E. A.; Catlow, C. R. A. J. Phys. Chem. Solids 1988, 49, 1225.

(26) Driscoll, D. J.; Martir, W.; Wang, J.-X.; Lunsford, J. H. J. Am. Chem. Soc. 1985, 107, 58.

(27) Kantorovich, L. N.; Holender, J. M.; Gillan, M. J. Surf. Sci. 1995, 343, 221.

(28) Ferrari, A. M.; Pacchioni, G. J. Phys. Chem. 1995, 99, 17010.

(29) Castanier, E.; Noguera, C. Surf. Sci. 1996, 364, 1.

(30) Ito, T.; Sekino, T.; Moriai, N.; Tokuda, T. J. Chem. Soc., Faraday Trans. 1 1981, 77, 2181.

(31) Ito, T.; Kuramoto, M.; Yoshioka, M.; Tokuda, T. J. Phys. Chem. 1983, 87, 4411 .

(32) Stefanovich, E. V.; Truong, T. N. J. Chem. Phys. 1995, 102, 5071

(33) Stevens, W. J.; Basch, H.; Krauss, M. J. Chem. Phys. 1984, 81, 6026.

(34) Pandey, R.; Zuo, J.; Kunz, A. B. J. Mater. Res. 1990, 5, 623.

(35) Vail, J. M.; Harker, A. H.; Harding, J. H.; Saul, P. J. Phys. C: Solid State Phys. 1984, 17, 3401.

(36) Frisch, M. J.; Trucks, G. W.; Schlegel, H. B.; Gill, P. M. W.; Johnson, B. G.; Wong, M. W.; Foresman, J. B.; Robb, M. A.; Head-Gordon, M.; Replogle, E. S.; Gomperts, R.; Andres, J. L.; Raghavachari, K.; Binkley, J. S.; Gonzalez, C.; Martin, R. L.; Fox, D. J.; Defrees, D. J.; Baker, J. Stewart, J. J. P.; Pople, J. A. Gaussian 92/DFT, Revision G.3; Gaussian, Inc.: Pittsburgh, PA, 1993.

(37) Ochs, D.; Maus-Friedrichs, W.; Brause, M.; Günster, J.; Kempter, V.; Puchin, V.; Shluger, A.; Kantorovich, L. Surf. Sci. 1996, 365, 557.

(38) Shluger, A. L.; Heifets, E. N.; Gale, J. D.; Catlow, C. R. A. J. Phys.: Condens. Matter 1992, 4, 5711.

(39) Abraham, M. M.; Unruh, W. P.; Chen, Y. Phys. Rev. B 1974, 10, 3540 .

(40) Eglitis, R. I.; Kuklja, M. M.; Kotomin, E. A.; Stashans, A.; Popov, A. I. Comput. Mater. Sci. 1996, 5, 298.

(41) González, R.; Pareja, R.; Chen, Y. Phys. Rev. B 1992, 45, 12730.

(42) JANAF Thermochemical Tables, J. Phys. Chem. Ref. Data. 1985 (Suppl. 1).

(43) Iwamoto, M.; Lunsford, J. H. J. Phys. Chem. 1980, 84, 3079.

(44) Takita, Y.; Lunsford, J. H. J. Phys. Chem. 1979, 83, 683.

(45) Hewett, K. B.; Anderson, L. C.; Rosynek, M. P.; Lunsford, J. H J. Am. Chem. Soc. 1996, 118, 6992.

(46) Coulter, K.; Goodman, D. W. Catal. Lett. 1992, 16, 191.

(47) Kantorovich, L. N.; Gillan, M. J. Surf. Sci., in press.

(48) Weast, R. C., Astle, M. J., Eds. CRC Handbook of Chemistry and Physics, 62nd ed.; CRC Press: Boca Raton, FL, 1981-1982.

(49) Nygren, M. A.; Pettersson, L. G. M. Chem. Phys. Lett. 1994, 230, 456.

(50) Huheey, J. E.; Keiter, E. A.; Keiter, R. L. Inorganic Chemistry: Principles of Structure and Reactivity; Harper Collins: New York, 1993; pp 42-43.

(51) Bauschlicher Jr., C. W.; Partridge, H. Chem. Phys. Lett. 1993, 208, 241.

(52) Borowski, P.; Roos, B. O.; Racine, S. C.; Lee, T. J.; Carter, S. J. Chem. Phys. 1995, 103, 266. 